\title{
Lipoid Proteinosis; A Case Report with Difficult Intubation
}

\author{
Syed Aftab Haider, Atqua Sultan, Salman Waris, Aatir Fayyaz, Zaira Salman
}

\begin{abstract}
Lipoid proteinosis is an autosomal recessive disorder and caused by the mutations of ECM1 (extracellular matrix protein 1) gene on chromosome 1q21. It is an autosomal recessive disorder that results in deposition of hyaline material under the skin, connective tissue and mucous membranes. Hoarseness of voice occurs in infancy or early childhood. There is also thickening of the tongue and pharynx. In this case report, we present a case of 27 years old female who was presented first for emergency Lower Segment Caesarean section (LSCS) and after five months of first operation for cholecystectomy.
\end{abstract}

This report is of interest for gynaecologists, anaesthesiologists and general surgeons regarding management of this rare entity patient.

KEYWORDS: Lipoid proteinosis, difficult intubation.

This article may be cited as: Haider SA, Sultan A, Waris S, Fayyaz A, Salman Z. Lipoid Proteinosis; A Case Report with Difficult Intubation. J Liaquat Uni Med Health Sci. 2018;17(01):57-9. doi: 10.22442/jlumhs.181710550

\section{INTRODUCTION}

Lipoid proteinosis also known as Urbach-Wiethe disease named on the name of Urbach and Wiethe, who first reported this rate disease in $1929^{1}$. It is an autosomal recessive disorder that results in deposition of hyaline material under the skin, connective tissue and mucous membranes, resulting in formation of scars, papules and nodules over the skin; papules on eyelid margins and hoarseness of voice in infancy or early childhood ${ }^{2,3}$. There is also thickening of the tongue and pharynx. It has been found that mutation of ECM1 gene on chromosome 1q21 at D14985 position is a cause of lipoid proteinosis ${ }^{4}$.

\section{CASE REPORT}

A 27 years female patient presented for emergency Lower Segment Caesarean section (LSCS) due to obstructed labour. She was having hoarseness of voice since infancy and typical skin lesions that developed at approximately seven years of age. In the following years, she had no history of seizures, visual disturbances, photosensitivity, or respiratory obstruction. She had bloated tongue with asymmetrical pearly white infiltrations. There were indiscriminate acneiform scars over the face and beaded papules on the thickened margins of the eyelids. There was no history of consanguinity. Patient although could hear but she had hearing aid at approximately 16 years of age. Patient didn't inform anaesthetist about this rare disease though she was diagnosed at 7 years of age by Dermatologist.
General Anaesthesia was given to patient and she had difficult intubation due to diffuse infiltration of pharynx and larynx. She was intubated with $5.5 \mathrm{~mm}$ cuffed endotracheal tube (ETT) although the exact size of ETT for patient was $7.0 \mathrm{~mm}$. Everything went uneventful but patient was unable to speak upto 2 months after LSCS. She gradually started producing incoherent voices and complete return of speech was there by 3 months with hoarseness as such persisting. This case was operated on January 05, 2017.

After 5 months: June 02, 2017, patient diagnosed to have cholelithiasis and was referred by surgeon to Anaesthesiologist for pre-operative evaluation regarding the patient concern for type of anaesthesia. It was planned that open cholecystectomy be done under regional Anaesthesia due to the difficulty of airway and loss of phonation due to GA. Both of these procedures were done in Nishtar Hospital Multan.

After Sterile skin preparation, inj. xylocaine $2 \% 3 \mathrm{ml}$ was locally infiltrated in skin. Using 27-gauge needle inj. bupivacaine $0.75 \%$ and injection buprenorphine 100 microgram was given in L3-L4 interspace. Desired level was T6 and was achieved. Surgery went uneventful and she could speak after surgery.

\section{DISCUSSION}

Urbach-Weithe disease was first time described in 1908 by Seibenmann and first case was reported in 1929 by Urbach and Weithe, these authors used the name "Lipoid proteinosis" for this disease ${ }^{1,5}$. Historically it was a disease of European ancestry" but 
now has spread worldwide. Up till now, about 300 or more cases have been reported worldwide ${ }^{6}$.

Lipoid proteinosis is an autosomal recessive disorder and caused by the mutations of ECM1 (extracellular matrix protein 1) gene on chromosome 1q21 ${ }^{4}$. The basic function of this gene 1 is still unclear. This mutation results in deposition of hyaline like material (periodic acid-Schiff positive (PAS-positive) hyaline material) in skin, connective tissue and sometimes in internal organs, resulting in formation of plaques, papules or ulcerated lesions over the skin and mucous membranes ${ }^{7}$.

There are no specific laboratory investigations to rule out lipoid proteinosis. On X-rays examination, we can see bilateral, para-cellular, constant calcifications ${ }^{2}$. On histological examination, we can see hyperkeratosis and asymmetrical acanthosis on epidermis ${ }^{8}$. Otolaryngeal manifestations of the disease were described by Savage et al. and they found that about two third of patients present with hoarseness of voice either at birth or in infancy period. Hoarseness of voice is the early and most common manifestation of laryngeal involvement in lipoid proteinosis. Sometimes thickening of the vocal cords and adjacent tissues is also seen. Many patients are unable to open full mouth and laryngoscopy is not possible ${ }^{9}$. In present case report there was also difficulty in opening the mouth and intubation was very difficult that why we used only $5.5 \mathrm{~mm}$ ETT for intubation.

There is no specific treatment available for lipoid proteinosis. Kaya $\mathrm{Tl}$ et $\mathrm{al}^{10}$, reported improvement in clinical and histological findings with D-penicillamine treatment. Some reports have suggested that Dimethyl Sulfoxide is effective for treating the symptoms of lipoid proteinosis ${ }^{11}$. A report suggested that Acitretin improves voice and laryngeal lesions ${ }^{12}$. A recent case report from Egypt has also confirmed the role of Acitretin in treatment of lipoid proteinosis and these authors successfully treated two children with diminution of all symptoms of the disease ${ }^{13}$. Surgical treatments with excision of the laryngeal lesions have been shown to be effective in improving the quality of life. In severe cases of lipoid proteinosis, tracheostomy can be done to save life ${ }^{1,2}$. All of these treatments can cure only a smaller portion of disease and no treatment is available to cure the disease in the whole body.

\section{CONCLUSION}

Patients having difficulty in opening of mouth and difficult intubation due to diffuse infiltration of pharynx and larynx should be evaluated for Lipoid Proteinosis. If significant evidence of the disease is found then general anesthesia should be avoided.

Disclosure: Consent was taken from the patient for publication of this case report.

\section{Conflict of Interest: None}

\section{REFERENCES}

1. Harper JI, Duguid KP, Staughton RC, Moffat D. Oropharyngeal and laryngeal lesions in lipoid proteinosis. J Laryngol Otol. 1983; 97(9):877-80.

2. Hamada T. Lipoid proteinosis. Clin Exp Dermatol. 2002; 27(8):624-9.

3. Dogramaci AC, Celik MM, Celik E, Bayarogullari $\mathrm{H}$. Lipoid proteinosis in the eastern Mediterranean region of Turkey. Indian J Dermatol Venereol Leprol. 2012; 78(3):318-22. doi: 10.4103/03786323.95447.

4. Hamada T, McLean WH, Ramsay M, Ashton GH, Nanda A, Jenkins $T$, et al. Lipoid proteinosis maps to $1 \mathrm{q} 21$ and is caused by mutations in the extracellular matrix protein 1 gene (ECM1). Hum Mol Genet. 2002; 11(7):833-40.

5. Savage MM, Crockett DM, McCabe BF. Lipoid proteinosis of the larynx: a cause of voice change in the infant and young child. Int $\mathrm{J}$ Pediatr Otorhinolaryngol. 1988;15(1):33-8.

6. Cote DN. Head and neck manifestations of lipoid proteinosis. Otolaryngol Head Neck Surg. 1998; 119(1):144-5.

7. Van Hougenhouck Tulleken W, Chan I, Hamada $\mathrm{T}$, Thornton $\mathrm{H}$, Jenkins $\mathrm{T}$, McLean $\mathrm{WH}$, et al. Clinical and molecular characterization of lipoid proteinosis in Namaqualand, South Africa. $\mathrm{Br} \mathrm{J}$ Dermatol. 2004; 151(2):413-23.

8. Baykal C, Topkarci Z, Yazganoglu KD, Azizlerli G, Baykan B. Lipoid proteinosis: a case series from Istanbul. Int J Dermatol. 2007; v46(10):1011-6.

9. Koganti D. Urbach-Wiethe Disease: A Rare Cause of Hoarseness of Voice. Int J Phonosurg Laryngol. 2013;3(2):61-4.

10. Kaya TI, Kokturk A, Tursen U, Ikizoglu G, Polat A. D-Penicillamine Treatment for Lipoid Proteinosis. Pediatr Dermatol. 2002; 19(4):359-62.

11. Gruber F, Manestar D, Stasic A, Grgurevic Z. Treatment of lipoid proteinosis with etretinate. Acta Derm Venereol. 1996; 76(2):154-5. 
12. Toosi S, Ehsani AH. Treatment of lipoid proteinosis with acitretin: a case report. J Eur Acad Dermatol Venereol. 2009; 23(4):482-3. doi: 10.1111/j.1468-3083.2008.02928.x.

13. Bakry OA, Samaka RM, Houla NS, Basha MA.
Two Egyptian cases of lipoid proteinosis successfully treated with acitretin. J dermatol Case Reports. 2014; 8(1):29-34. doi: 10.3315/ jdcr.2014.1168

AUTHOR AFFILIATION:
Dr. Syed Aftab Haider (Corresponding Author)
Assistant Professor of Anesthesia
Intensive Care Unit and Pain Management
Nishtar Medical University/Hospital Multan, Pakistan.
Email: draftab.nishtar@gmail.com
Dr. Atqua Sultan
Nishtar Medical University/Hospital Multan, Pakistan.
Dr. Salman Waris
Professor of Anesthesia
Intensive Care Unit and Pain Management
Nishtar Medical University/Hospital Multan, Pakistan.
Dr. Aatir Fayyaz
Consultant Anesthesiologist at The Children's Hospital \&
The Institute Of Child Health, Multan, Pakistan.
Dr. Zaira Salman
Nishtar Medical University/Hospital Multan, Pakistan.

